
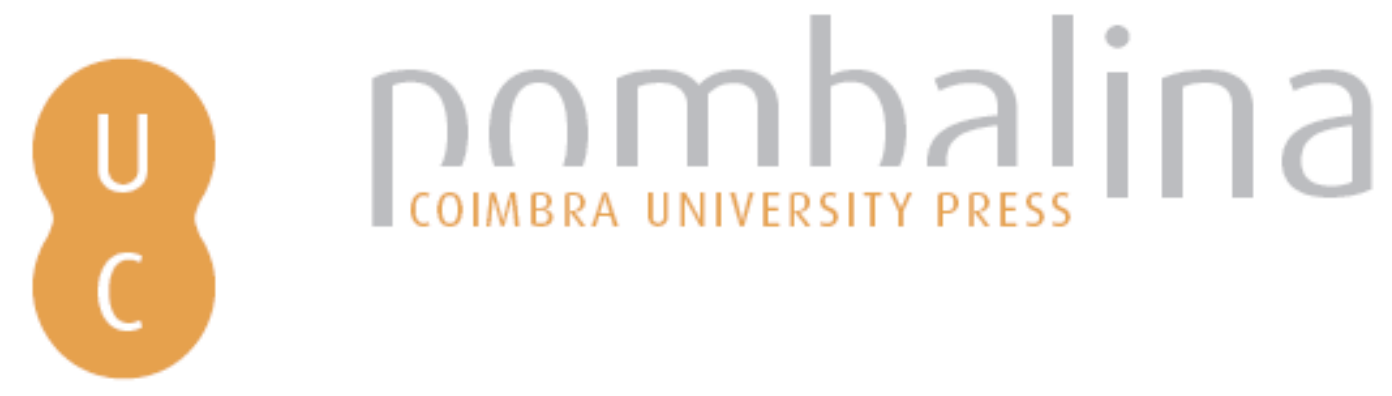

\title{
Minimum travel time algorithm for fire behavior and burn probability in a parallel computing environment
}

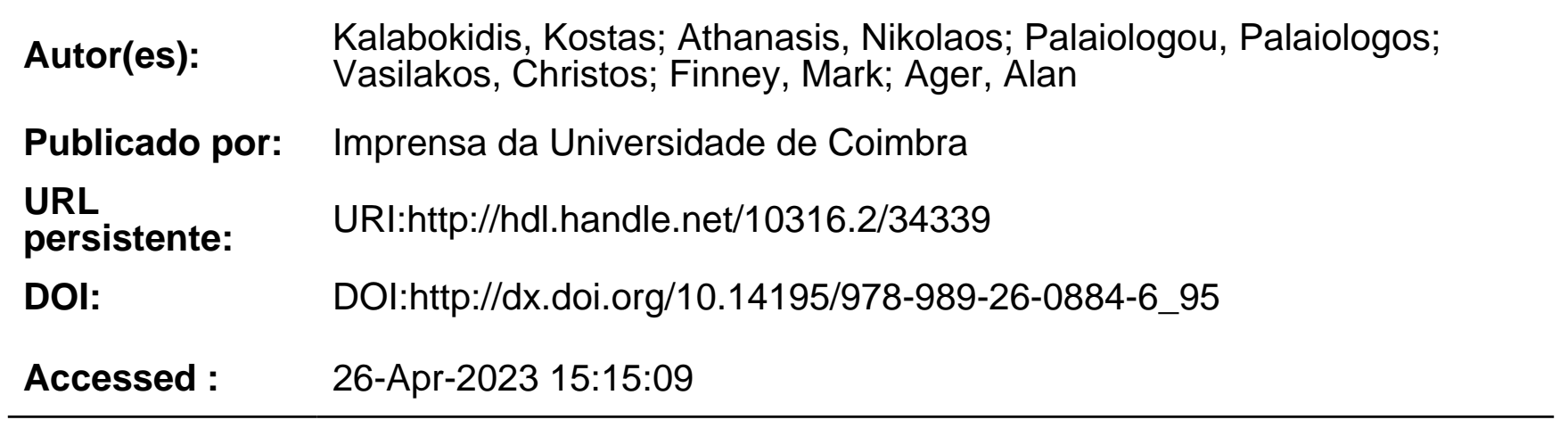

A navegação consulta e descarregamento dos títulos inseridos nas Bibliotecas Digitais UC Digitalis, UC Pombalina e UC Impactum, pressupõem a aceitação plena e sem reservas dos Termos e Condições de Uso destas Bibliotecas Digitais, disponíveis em https://digitalis.uc.pt/pt-pt/termos.

Conforme exposto nos referidos Termos e Condições de Uso, o descarregamento de títulos de acesso restrito requer uma licença válida de autorização devendo o utilizador aceder ao(s) documento(s) a partir de um endereço de IP da instituição detentora da supramencionada licença.

Ao utilizador é apenas permitido o descarregamento para uso pessoal, pelo que o emprego do(s) título(s) descarregado(s) para outro fim, designadamente comercial, carece de autorização do respetivo autor ou editor da obra.

Na medida em que todas as obras da UC Digitalis se encontram protegidas pelo Código do Direito de Autor e Direitos Conexos e demais legislação aplicável, toda a cópia, parcial ou total, deste documento, nos casos em que é legalmente admitida, deverá conter ou fazer-se acompanhar por este aviso.

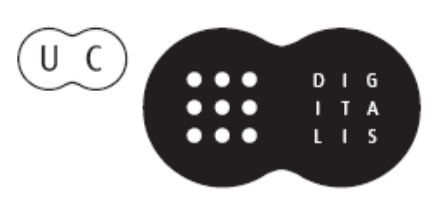




\section{ADVANCES IN}

Forest Fire

\section{RESEARCH}

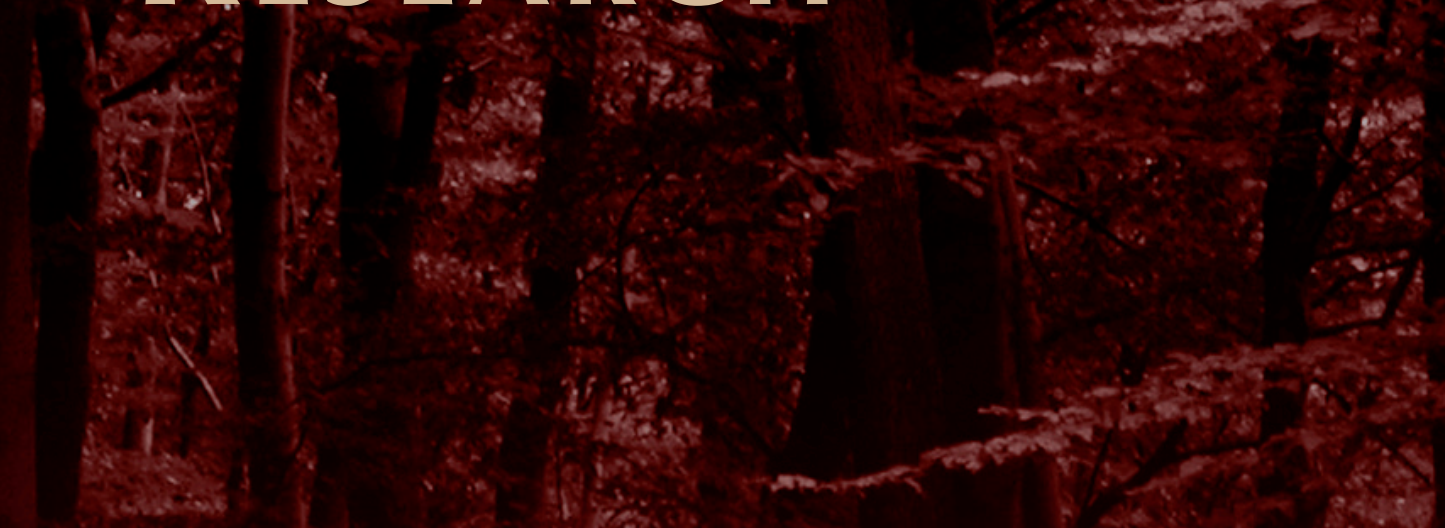

\section{DOMINGOS XAVIER VIEGAS}

\section{EDITOR}




\title{
Minimum travel time algorithm for fire behavior and burn probability in a parallel computing environment
}

\author{
Kostas Kalabokidis', Nikolaos Athanasis ${ }^{a}$, Palaiologos Palaiologou ${ }^{a}$, \\ Christos Vasilakos ${ }^{\mathrm{a}}$, Mark Finney ${ }^{\mathrm{b}}$, Alan Ager \\ ${ }^{a}$ Department of Geography, University of the Aegean, GR-81100 Mytilene, GREECE. \\ kalabokidis@aegean.gr \\ ${ }^{b}$ USDA Forest Service, Rocky Mountain Research Station, Fire Sciences Laboratory, 5775 Hwy 10 \\ West, Missoula,MT 59808,USA, mfinney@fs.fed.us \\ ${ }^{c}$ USDA Forest Service, Pacific Northwest Research Station, Western Wildlands Environmental \\ Threat Assessment Center, 3160 NE 3rd Street, Prineville, OR 97754, USA, aager@fs.fed.us
}

\begin{abstract}
Fire management systems materialize the integration of fire science models and decision support planning modules. Their operational usage often requires the concurrent execution of a large number of fire growth simulations by multiple users. Intensive computations such as the creation of burn probability maps demand not only high expertise but also high computing power and data storage capacity.

The purpose of this paper is to present some of the initial results of the AEGIS platform, which is a Web-GIS wildfire prevention and management information system currently under development. More specifically, the paper focuses on the utilization of the Minimum Travel Time (MTT) algorithm as a powerful fire behavior prediction system. MTT in AEGIS will be applied in a transparent way through its graphical user interface. Several end users will be able to conduct on-demand fire behavior simulations. To achieve this, end users must provide a minimum amount of inputs, such as fire duration, ignition point and weather information. Weather inputs can be either inserted directly or derived from selected remote automatic weather stations or forecasted weather data maps based on the SKIRON system (Eta/NCEP model).

Seasonal burn probability maps will be also prepared and provided to the end users. Socioeconomic data, weather predictions, topographic and vegetation data will be combined with artificial neural networks to produce an ignition probability map. Based on the ignition probability map, thousands of potential ignition points located in areas of anticipated high risk will be generated. These ignitions will be further used as inputs on MTT simulations, running FConstMTT as a command line-based executable. FConstMTT calculations will be conducted on a parallel mode in Microsoft Azure infrastructure using a different subset of ignition points in each simulation.

The current deployment of the AEGIS platform consists of a number of machines resided on premises and a scalable Cloud Computing environment based on the Microsoft Azure infrastructure. This parallel computing environment ensures high processing power availability and high data storage capacity. During a fire emergency, the scalability of the Cloud can also provide extra processing power and storage, if needed. It is anticipated that by integrating MTT into the AEGIS platform, the firefighting and civil protection agencies will gain great assistance to organize better and more reliable plans for fire confrontation.
\end{abstract}

Keywords: Minimum Travel Time (MTT); Ignition Risk; Wildfire Behavior; Burn Probabilities; FConstMTT; Cloud Computing; Web-GIS

\section{Introduction}

Large wildfires break out on an annual basis causing problems for societies and firefighting agencies across several fire prone areas of the world. Information technology provides the means for the utilization of sophisticated solutions on pre-fire management and planning, post-fire effects mitigation and potential wildfire behavior evaluation. 
Towards the development of effective fire management operational systems, the integration and utilization of fire behavior and risk models and decision support planning modules plays an important role. Today's firefighting needs demand systems that are able to conduct on a timely manner and without devastating delays multiple concurrent fire behavior predictions for several different users of fire suppression and civil protection agencies involved. However, this kind of operation requires trained and skilled operators with expertise in fire propagation simulation and behavior modeling. In advance, substantial computing resources are required to conduct these intense spatiotemporal calculations; nevertheless, local civil protection agencies often do not own these resources due to limited financial means (Kalabokidis et al. 2014).

To deal with the aforementioned issues, the Web-GIS wildfire prevention and management information system AEGIS is currently under development. AEGIS will be a cost effective, easy to use forest fire management system that will utilize the Minimum Travel Time (MTT) algorithm (Finney 2002) as a powerful and sophisticated cell-based tool for fire behavior predictions, fuel treatments and fire risk estimation. The MTT algorithm is applied in strategic and tactical fire management planning throughout the United States (Andrews 2009) integrated into the Wildland Fire Decision Support System (WFDSS) (Pence and Zimmerman 2011). It actually typifies wildfires in the Mediterranean region, which are relatively short in duration with respect to those in the western USA. AEGIS is applied on seven study areas of Greece with different environmental and socioeconomic characteristics.

The scope of this paper is to present some of the initial results of MTT incorporation into the AEGIS platform. MTT in AEGIS is applied in a transparent way through a Web-GIS platform for a single fire simulation. Several end users are able to conduct concurrently on-demand fire behavior simulations by providing a minimum amount of inputs, such as fire duration, ignition point and weather data. Beside the predefined weather data by the user, the simulation can be also based either on real weather data retrieved from Remote Automatic Weather Station (RAWS) of the study area or can be based on predicted weather conditions retrieved from a weather prediction model that supports the platform.

Seasonal burn probability and flame length maps are automatically generated periodically (when the weather pattern is suspected to change), by simulating thousands of possible wildfire ignitions across each study area. Simulations are conducted by applying parallel computer processing techniques of High Performance Computing (HPC) that resides on premises and/or Cloud Computing of Microsoft Azure. ArcGIS Server is utilized for storing the outputs in geo-databases and creating the visualization services that enables end-users to see the results in the Web-GIS platform over high resolution satellite Bing Maps ${ }^{1}$.

\section{The Minimum Travel Time algorithm}

The MTT algorithm can either compute the potential fire behavior characteristics (spread rate, fireline intensity, time of arrival, flow paths, etc.) for a single fire or burn probabilities/ flame length for the entire landscape from thousands of simulated fires based on landscape data, weather and fuel moisture information. The fire perimeters created by MTT are similar to wave-front expansion (Richards 1990; Finney 2002), but they are mathematically and computationally more efficient. Holding all environmental conditions constant, the MTT algorithm searches for the fastest path of fire spread along straight-line transects connected by nodes (cell corners) (Finney 2006) and it exposes the effects of topography and arrangement of fuels on fire growth (Ager and Finney 2009).

The MTT algorithm replicates fire growth by the Huygens' Principle, where the fire edge growth (and behavior) is a vector or wave front (Richards 1990; Finney 2002). While holding environmental

${ }^{1}$ http://www.bing.com/maps 
conditions constant, fire growth calculation exposes the effects of topography and arrangement of fuels on fire growth (Ager and Finney 2009). Extensive testing over the years has demonstrated that the Huygens' Principle, originally incorporated into FARSITE (Finney 1998) and later approximated in the more efficient MTT algorithm, can accurately predict fire spread and replicate large fire boundaries on heterogeneous landscapes (Ager et al. 2010; Arca et al. 2007; Carmel et al. 2009).

In addition to fire spread that is predicted when a new fire spot is provided, MTT has the advantage of producing the burn probability of the entire study area by simulating thousands of potential fires that could burn throughout the area. It permits Monte Carlo simulations of many fires $(>100,000)$, to evaluate burn probability and fire intensity for very large ( $>2$ million ha) landscapes (Ager and Finney 2009). Burn probability is an estimate of the likelihood of a pixel burning given a single random ignition under burn conditions in the simulation. The likelihood measures are required for quantitative risk assessments. Burn probability modeling represents a major advancement in wildfire behavior modeling compared to previous methods, such as those where fire likelihood was quantified with relatively few $(<10)$ predetermined ignition locations. As a result, the product of this process is the burn probability map that reveals which areas are more susceptible to encounter a fire event and which are less.

\section{Methodology}

The system architecture is structured by combining different on-premises and Cloud resources. On demand single fire simulations are conducted inside an on-premise Datacenter, while seasonal burn probability outputs are initially calculated in four Virtual Machines (VMs) in the Cloud infrastructure of Microsoft Azure (8x cores machines, $14 \mathrm{~GB}$ RAM, 1.6 GHz) and then finalized in an on-premise HPC cluster environment (24x cores machines, $8 \mathrm{~GB}$ RAM, $2.9 \mathrm{GHz}$ ) that contains $4 \mathrm{VMs}$. All fire behavior outputs are handled and visualized by using an ArcGIS Server deployment, installed on premises.

For the creation of the burn probability maps, cloud resources are utilized on specific time frames, when the weather pattern is suspected to change. During such a time frame, the VMs in the Cloud are allocated and command line-based executables of MTT (called FConstMTT) are running simultaneously on each VM. On the other hand, on demand fire simulations are better suited to run on premises than in the Cloud. This is because of the significant amount of time overhead (approximately $15 \mathrm{~min}$ ) required to allocate new VMs in Microsoft Azure. On demand fire behavior simulations need to be conducted instantly and thus, time overheads should be minimized to achieve a timely and effective response when a wildfire breaks out.

After the execution in the Cloud's and/or on-premises VMs, output results are handled by the ArcGIS Server on premises which enables the visualization of the results from the graphical interface of AEGIS (Figure 1). 


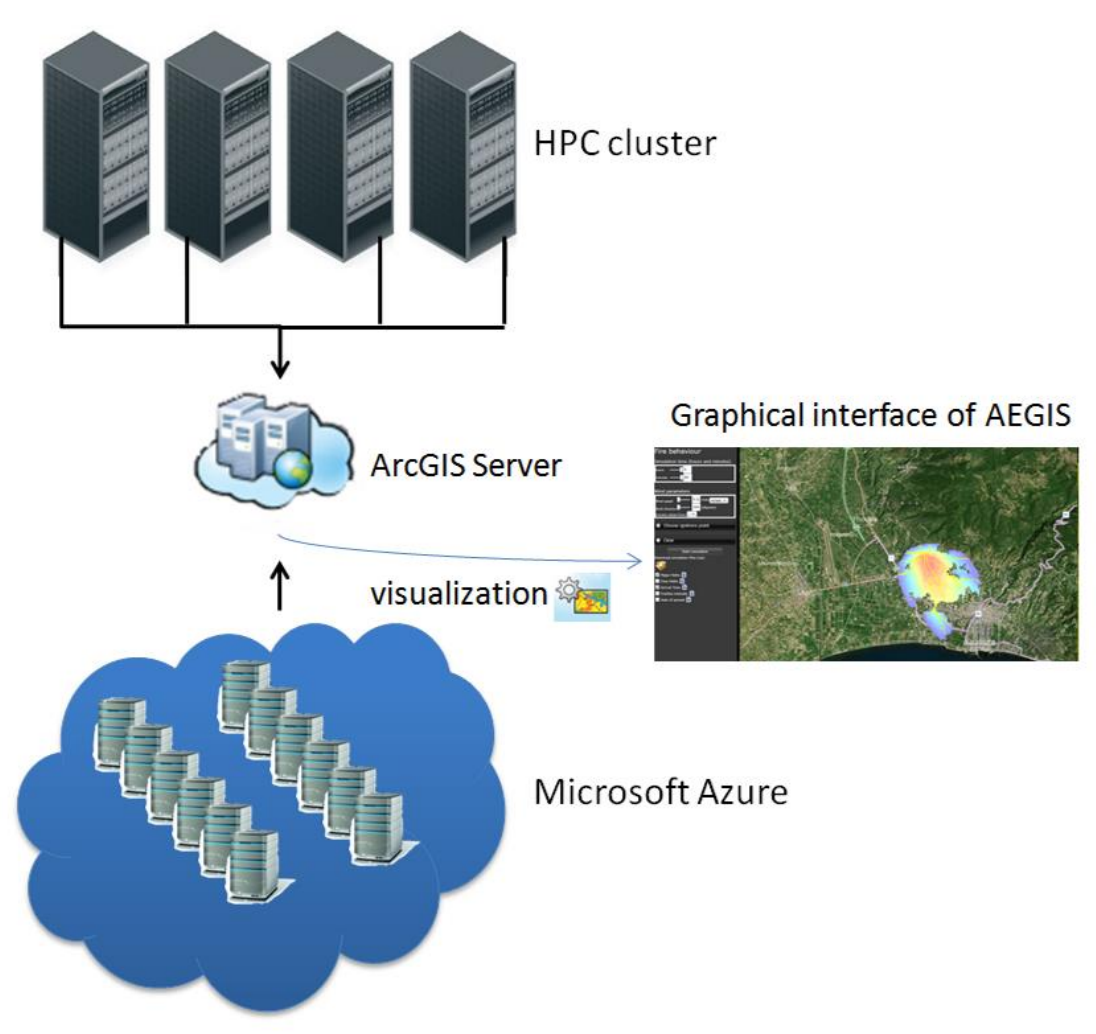

Figure 1. Combining Cloud resources and HPC for simulating fire behavior and burn probability in AEGIS

\section{Running on demand fire simulations}

When a new fire simulation is triggered, a command line execution of MTT is starting. If multiple users begin their fire simulations simultaneously, each simulation will be assigned to one of the available VMs and execution takes place in parallel. Before the execution starts, a configuration file is generated on the fly that stores all the necessary input parameters of the simulation (duration, wind speed and direction). Similar to FARSITE simulations, conditional fuel moisture is calculated by providing the corresponding weather and wind files. These files are automatically created if a conditioning period is defined, calculated from RAWS data of the past five days. If the user does not define a preferable RAWS, then the system automatically finds the closest to the fire ignition. Users have also the ability to use forecasted wind data from the closest gridded prediction point provided by the weather forecast prediction model called SKIRON, based on Eta/NCEP model (Kallos et al. 1997). Upon the completion of execution, several output files are generated either in ascii format (arrival time, fireline intensity, ignition point and rate of spread) or vector files with information for regular and major flow paths. After the creation of the output files, several ArcGIS Server geoprocessing services are running to transform ascii files to vector and to store them in corresponding ArcSDE geodatabase feature classes. Data from different users are separated by providing the user name and execution date and time. Finally, ArcGIS Server mapping services retrieve the appropriate information from the geo-database feature classes, by performing filtering that request's the corresponding simulation outputs and then, visualize them over the AEGIS platform.

In Figure 2, the architecture behind the on demand MTT execution is explained. End users trigger a new simulation (step 1) and then, the first available machine retrieves the input parameters and starts a new process of MTT execution (step 2). Outputs are stored in a shared repository (step 3) from where a geo-processing service retrieves them (step 4), performs the necessary data transformations, adds descriptive information, stores them in a geo-database (step 5) and, finally, notifies the users that the 
execution is finished. Visualization of the results is achieved by mapping services directly over the AEGIS graphical interface (step 6).

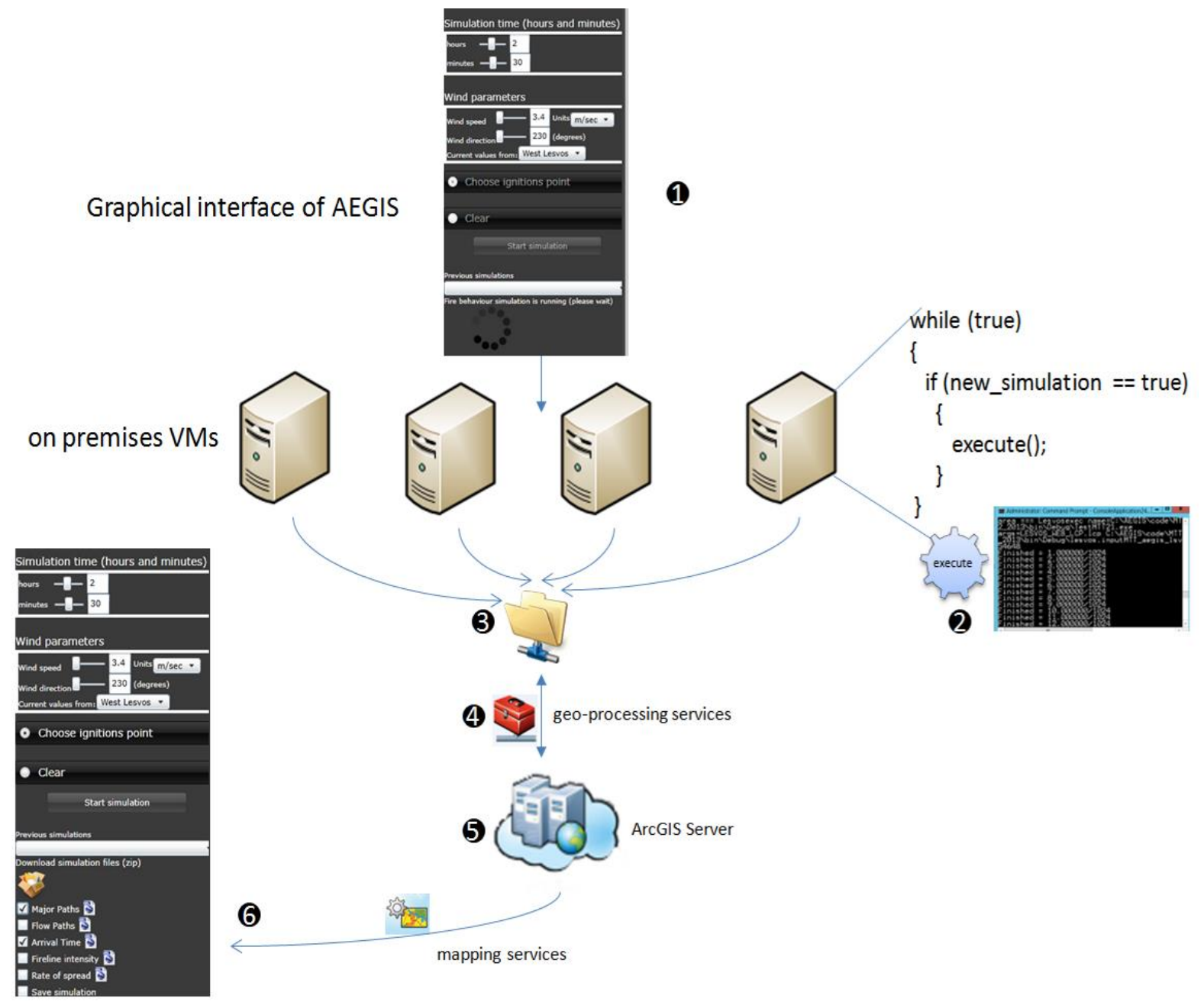

Figure 2. Information flow for on demand MTT simulations

\section{Running MTT for fire burn probabilities}

Conducting an on-premise FConstMTT simulation for a single study area takes approximately 24 hrs to be completed $\left(3,000 \mathrm{~km}^{2}, 30 \mathrm{~m}\right.$ cell size, 100,000 fires). This extraordinary execution time reveals the need for a parallel processing approach, to make the results available on a timely manner for each of the seven study areas. The phases for conducting a parallel processing FConstMTT simulation on Microsoft Azure cloud infrastructure are the following:

1. Initialization. A deployment is uploaded in the Microsoft Azure cloud infrastructure. The deployment encapsulates the FConstMTT command line-based executable.

2. Execution. Parallel execution of the FConstMTT executable is conducted, by dividing the overall number of ignition points (i.e. 100,000) equally among the available VMs. This partitioning of the ignitions significantly reduces the execution time.

3. Merging. The output results are combined into a new ascii text file to calculate the burn probabilities and the flame length categories (i.e. 20 categories) for the entire number of ignitions. 
4. Extraction. The burn probability and every flame length category are extracted from the merged output.

5. Visualization. The extracted outputs are loaded in a geo-database to be visualized through the AEGIS platform. Furthermore, outputs are available for download from the end-users to perform meta-analysis on them (e.g. with ArcFuels).

At the initialization phase, a .NET deployment is uploaded in the Microsoft Azure cloud. The deployment encapsulates the FConstMTT binary executable. Once the deployment has been uploaded, execution of the executable is starting concurrently in four VMs in the Cloud. Each of the VMs starts a new process that initializes the executable. With a total number of 100,000 ignition points, each of the VMs is running FConstMTT with 25,000 of them. Every FConstMTT calculation produces a flame length probability file that contains for each calculation point the corresponding burn probability and flame length probabilities for each of 20 flame length classes. Currently, the ignition points are generated randomly across each study area. However, it is planned to locate the ignition points based on an ignition probability map in areas of anticipated high risk. Socioeconomic data, weather predictions, topographic and vegetation data will be combined with artificial neural networks (Vasilakos et al. 2007; 2009) to produce a daily fire ignition probability map.

After the parallel execution of the executables, the intermediate results are combined together and merged. For this merging, the calculated burn probability is transformed to total numbers of burnings on each pixel, a methodology described in Kalabokidis et al. (2014). If t1, t2, t3 and t4 are the total numbers a pixel is burned from each FConstMTT calculation, the mean burn probability (BP) for each pixel is calculated as:

where:

$$
B P=\frac{(t 1+t 2+\cdots+t N)}{(f 1+f 2+\cdots f N)}=\frac{\Sigma_{i=\mathbf{1}}^{N} t_{\mathbf{i}}}{\sum_{i={ }_{\mathbf{1}}}^{N} f i}
$$

- $\quad N$ is the number of the available machines in the Cloud (in the current deployment $\mathrm{N}=4$ )

- $f i$ is the fraction of the total fire ignition points (in the current deployment $\mathrm{f}=25,000$ )

- $t_{i}$ is the partial number of burnings, calculated at the $\mathrm{i}^{\text {th }} \mathrm{VM}$.

In a similar way, the mean flame length probability (FLP) for each flame length category is calculated as:

$$
F L P=\frac{\Sigma_{i=\mathbf{1}}^{N} t i}{B P}
$$

Given the FLP, the conditional flame length (CFL) is calculated as:

$$
C F L=0.25 \times F I L 1+0.75 \times F I L 2+1.25 \times F I L 3+\cdots+9.75 * F I L 20
$$

After the calculation of the (1), (2) and (3) for each pixel of the study area, the values are stored in a file with the following structure:

\begin{tabular}{|cccccccc|}
\hline XPOS, & YPOS, & BP & FLP1, & FLP 2, & $\ldots$ & FLP 20, & CFL \\
$\mathrm{X}_{\mathrm{ij},}$ & $\mathrm{Y}_{\mathrm{ij}}$, & BP $_{\mathrm{ij}}$, & FLP $1_{\mathrm{ij}}$, & FLP $2_{\mathrm{ij}}$, & $\ldots$ & FLP 20 $0_{\mathrm{ij}}$, & CFL $_{\mathrm{ij}}$ \\
\hline
\end{tabular}

From this merged file, 22 separated ascii output files are generated (one output file for the burn probability, 20 output files for the flame length probabilities and one CFL output file). This extraction takes place in parallel on the HPC cluster environment. Each machine reads the merged file, extracts and transforms one of the categories in a corresponding file. Every file contains three columns: the latitude and longitude of the ignition point and the value of the corresponding category. After the extraction, the GDAL/OGR utility is used to convert each file to raster format. Geo-processing services 
retrieve the raster files and store them in a corresponding geo-database to visualize them over the AEGIS graphical interface through corresponding mapping services. In Figure 3, the information flow for the creation of a seasonal burn probability map in AEGIS is presented. At a specific time, the deployment is uploaded from one of the on-premises machines to the Cloud (step 1). Execution starts concurrently at available VMs (step 2). Partial output results are created and a merged file is generated that stores all values for all output categories (step 3). From the merged file, all output categories are extracted in separated output files (step 4), converted to raster files (step 5) and stored in a geo-database (step 6) for visualization purposes (step 7).

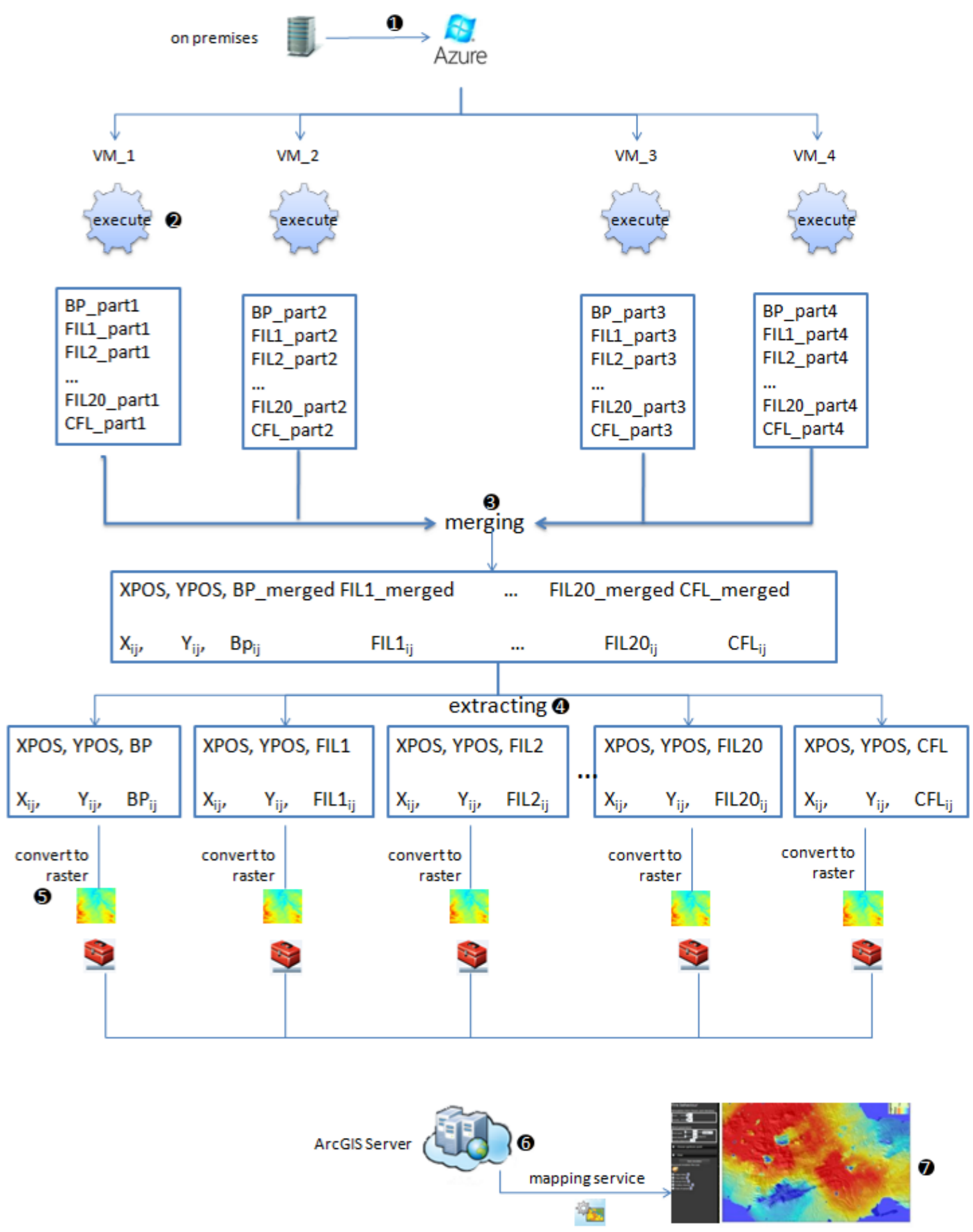

Figure 3. Information flow for the conduction of burn probabilities maps 


\section{Visualization of MTT results in AEGIS}

Authorized users of AEGIS are able to conduct new MTT simulations or view older stored simulations. If the user decides to conduct a new simulation, the ignition point and the duration time (hrs and min) of the simulation must be specified. The duration time cannot exceed six hrs, since MTT provides better simulations for short term time periods. Real-time wind parameters (speed and direction) are retrieved from RAWS of the study area or can be user-specified to conduct "what if" scenarios simulations. After providing the required inputs, users can trigger the "Start Simulation" button. The platform steadily provides information about the status of the simulation for as long as the execution is in progress. At the end of the simulation, all outputs can be directly visualized over the AEGIS platform by enabling a checkbox next to each mapped attribute. Individual output files can also be downloaded as $\mathrm{kml}$ layers or alternatively, can be downloaded in their raw format as a zip file (flow paths, major flow paths, fireline intensity, rate of spread, time of arrival and ignition point). In Figure 4, a visualization of MTT fire simulation from the AEGIS GUI is portrayed (arrival time and major flow paths). Simulation time was set to three hrs, while wind data were retrieved from a nearby RAWS. The check box "store the simulation" is used to store the simulation in the simulations archive.

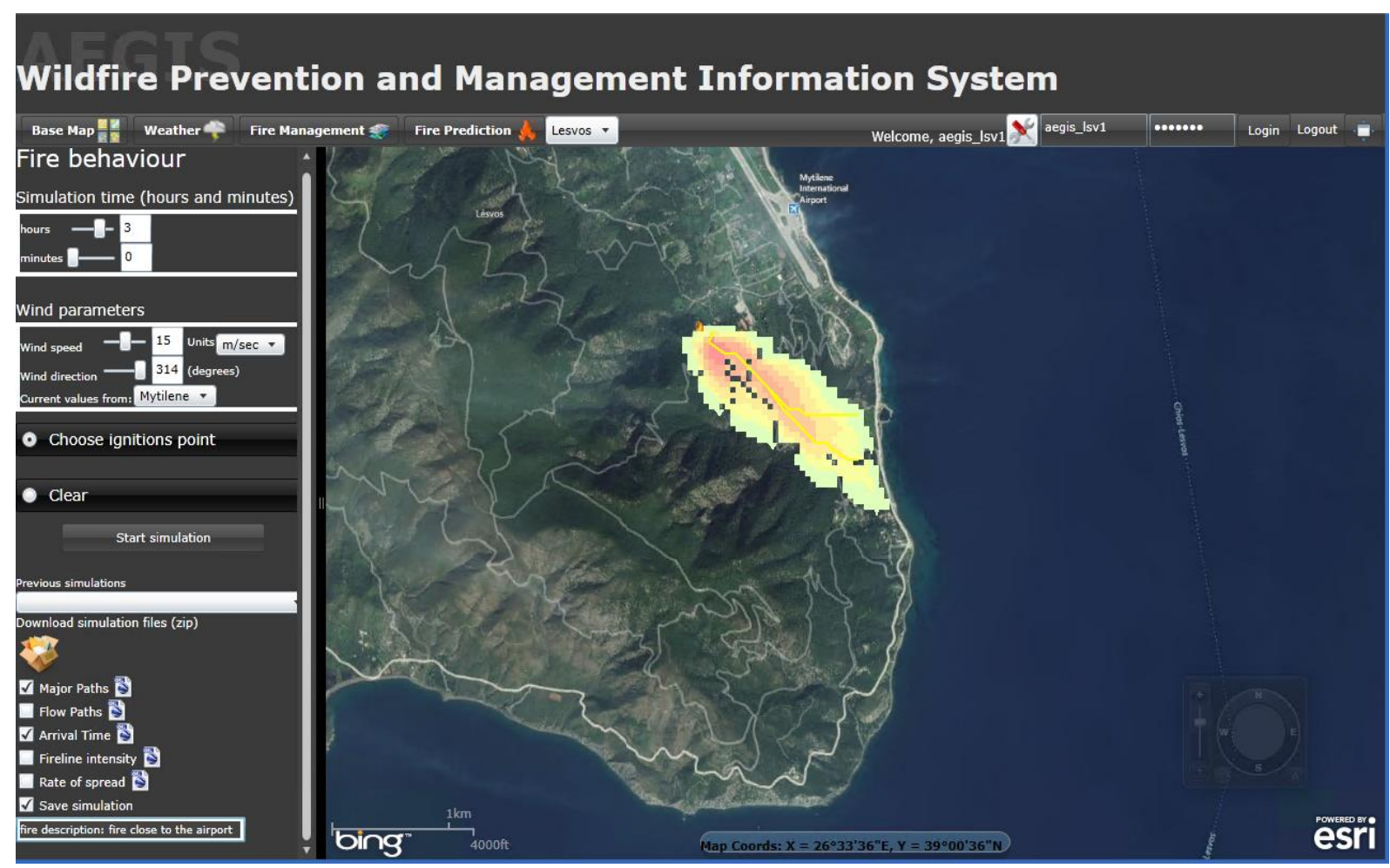

Figure 4. Visualization of on demand MTT results in AEGIS

Seasonal FConstMTT outputs can be visualized by selecting the desired attribute (mean burn probability, conditional flame length and each flame length class probabilities) from a drop down menu (Figure 5). 


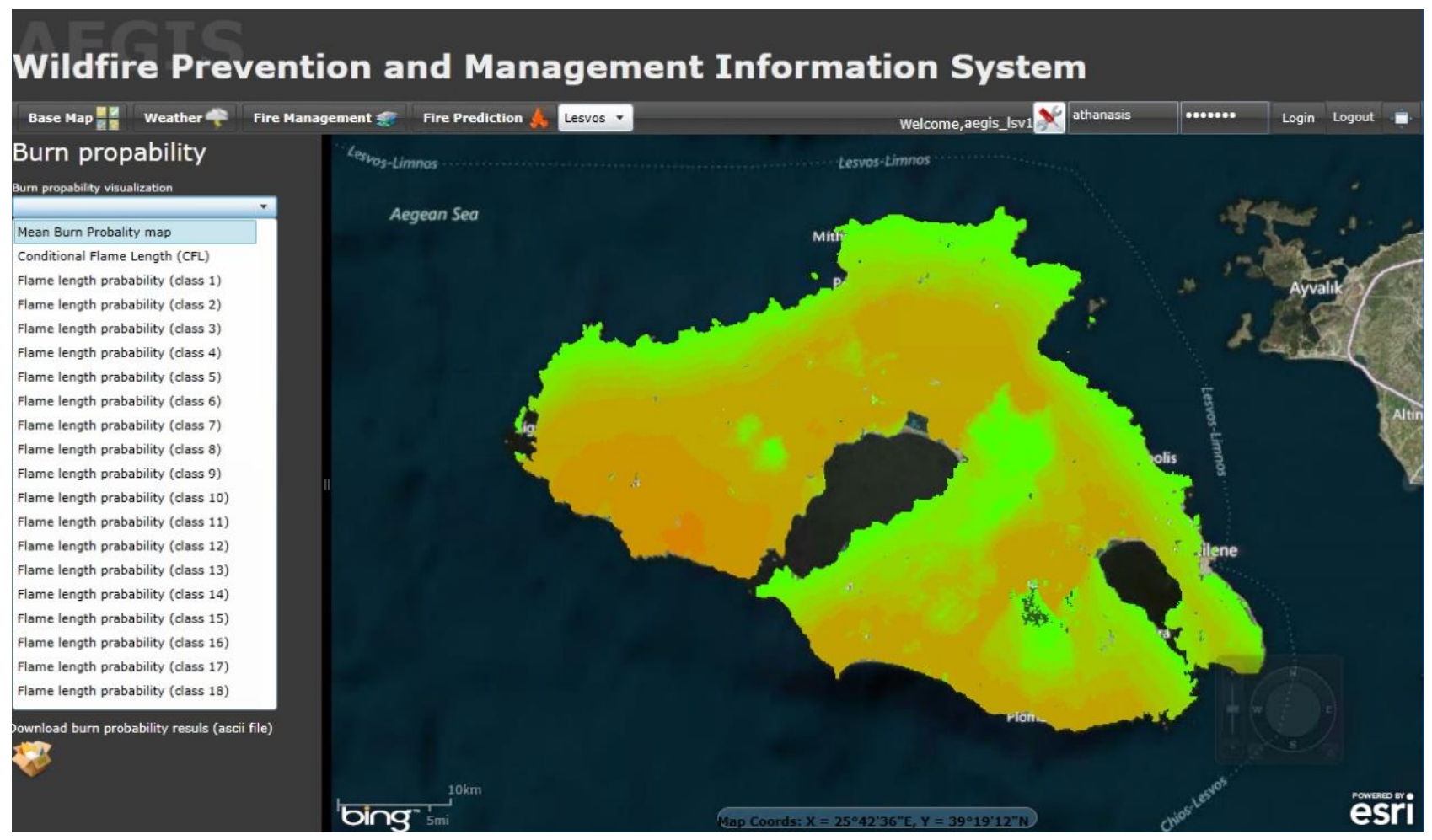

Figure 5. Visualization of burn probabilities in AEGIS

\section{Conclusions}

This paper describes the utilization of the fire behavior prediction algorithm of Minimum Travel Time (MTT) algorithm in the AEGIS platform. Calculations are conducted in a parallel computing environment, combining Cloud and HPC resources. More specifically, on demand fire simulations are conducted on premises, while seasonal burn probability maps are first conducted in the Cloud infrastructure of Microsoft Azure and then finalized in the HPC cluster environment. This combination of cloud and HPC resources provides the means to produce useful fire prediction maps without devastating delays.

On an operational basis, the system's functionalities may assist local authorities of wildfire management to extract useful information towards the design of an effective operational wildfire prevention and management plan. Fire behavior predictions are visualized through the web-based front end of AEGIS, eliminating the need to install special desktop software. Users have the ability, without the requirement of knowing the handling of complicated fire management systems, to integrate fire science models and decision support planning modules and to utilize the capabilities of the system.

The visualization of burn probability maps can reveal which areas are more susceptible to encounter a wildfire event. Furthermore, multiple on demand simulations can be conducted simultaneously by changing the weather parameters and simulate different "what if" scenarios. During a fire emergency, the fire behavior can be easily simulated by integrating real time weather measurements. The computation architecture follows the software design principles of parallel processing of high performance computing and cloud computing. All software modules are developed in the .NET language. Execution requires also third-party software of the MTT binary executables. By integrating MTT into the AEGIS platform for all seven study areas of AEGIS, firefighting and civil protection agencies may gain a great assistance to organize better and more reliable plans for fire confrontation. 


\section{Acknowledgments}

The research project "AEGIS: Wildfire Prevention and Management Information System" \{Code Number 1862\}, is implemented within the framework of the Action ARISTEIA of the Operational Program "Education and Lifelong Learning" (Action's Beneficiary: General Secretariat for Research and Technology), and is co-financed by the European Social Fund (ESF) and the Greek State. Final results and outcomes of the project are expected by September 2015.

\section{References}

Ager, A.A. and Finney, M.A., 2009. Application of wildfire simulation models for risk analysis. Geophysical Research Abstracts, 11, (2009) (EGU2009-5489, 2009; EGU General Assembly 2009).

Ager, A.A., Vaillant, N.M., Finney, M.A., 2010. A comparison of landscape fuel treatment strategies to mitigate wildland fire risk in the urban interface and preserve old forest structure. Forest Ecology and Management, 259, 1556-1570.

Andrews, P.L., 2009. BehavePlus fire modeling system, version 5.0: Variables. USDA Forest Service, Rocky Mountain Research Station, General Technical Report RMRS-GTR-213.

Arca, B., Duce, P., Laconi, M., Pellizzaro, G., Salis, M., Spano, D., 2007. Evaluation of FARSITE simulator in Mediterranean maquis. International Journal of Wildland Fire, 16, 563-572.

Carmel, Y., Paz, S., Jahashan, F., Shoshany, M., 2009. Assessing fire risk using Monte Carlo simulations of fire spread. Forest Ecology and Management, 257, 370-377.

Finney, M.A., 2002. Fire growth using minimum travel time methods. Canadian Journal of Forest Research 32, 1420-1424.

Finney, M.A., 1998. FARSITE: fire area simulation model development and evaluation. USDA Forest Service, Rocky Mountain Research Station, Research Paper RMRS-4.

Finney, M.A., 2006. An overview of FlamMap fire modeling capabilities. In: Proceedings of Fuels Management-How to Measure Success, Portland Oregon, USA, 28-30 March, pp. 213-220.

Kalabokidis K., Athanasis N., Vasilakos C. and Palaiologou P., 2014. Cloud Computing in Geospatial Analysis of Wildfire Danger and Fire Growth. In Wade DD \& Fox RL (Eds), Robinson ML (Comp): Proceedings of 4th Fire Behavior and Fuels Conference, 18-22 February 2013, Raleigh, NC, USA and 1-4 July 2013, St. Petersburg, Russia. Published by the International Association of Wildland Fire: Missoula, MT, USA. pp. 457-467.

Kalabokidis, K., N. Athanasis, C. Vasilakos, P. Palaiologou. 2014. Porting of a wildfire risk and fire spread application into a cloud computing environment. International Journal of Geographical Information Science, 28(3), 541-552.

Kallos, G., Nickovic, S., Papadopoulos, A., Jovic, D., Kakaliagou, O., Misirlis, N., Boukas, L., Mimikou, N., Sakellaridis, G., Papageorgiou, J., Anadranistakis, E. Manousakis, M., 1997. The regional weather forecasting system SKIRON: An overview. In Proceedings of the International Symposium on Regional Weather Prediction on Parallel Computer Environments, Athens, Greece, pp. 109-122.

Pence, M., Zimmerman, T., 2011. The wildland fire decision support system: Integrating science, technology, and fire management. Fire Management Today 71, 18-22.

Richards, G.D., 1990. An elliptical growth model of forest fire fronts and its numerical solution. International Journal for Numerical Methods in Engineering, 30, 1163-1179.

Vasilakos, C., Kalabokidis, K., Hatzopoulos, J., Kallos, G. and Matsinos, Y., 2007. Integrating new methods and tools in fire danger rating. International Journal of Wildland Fire, 16(3), 306-316.

Vasilakos, C., Kalabokidis, K., Hatzopoulos, J. and Matsinos, Y., 2009. Identifying wildland fire ignition factors through sensitivity analysis of a neural network. Natural Hazards, 50(1), 125-143. 